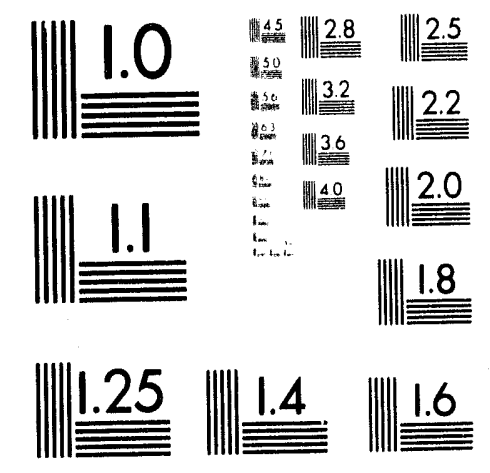



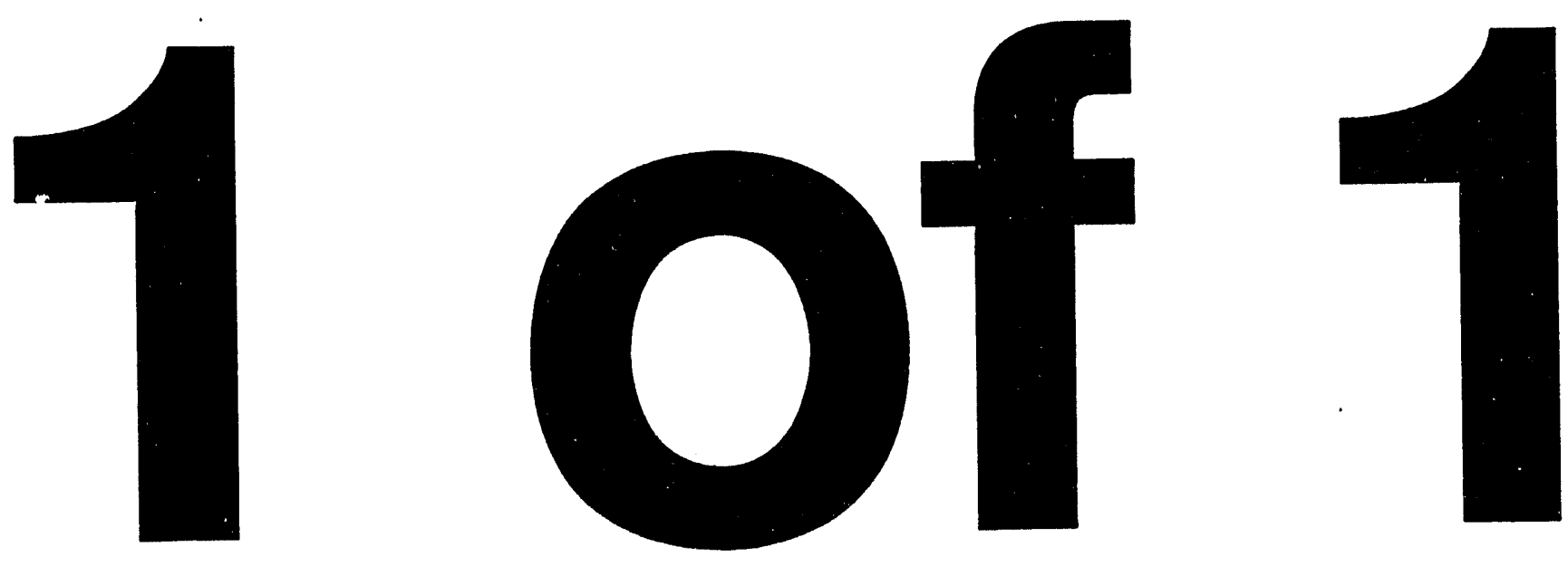
$(\cos 4-9.312 .35)-2$

UCRL-JC-113982

PREPRINT

\section{Precision and Manufacturing at the \\ Lawrence Livermore National Laboratory}

Theodore T. Saito

Richard J. Wasley

Irving F. Stowers

Robert R. Donaldson

Daniel C. Thompson

This paper was prepared for submittal to the

Technology 2003

NASA's Fourth National Technology Transfer Conference and Exposition Anaheim, California

December 7-9, 1993

November, 1993

This is a preprint of a paper intended for publication in a journal or proceedings. Since changes may be made before publication, this preprint is made available with the understanding that it will not be cited or reproduced without the permission of the author. 


\section{DISCLAIMER}

This document was prepared as an account of work sponsored by an agency of the United States Government. Neither the United States Govermment nor the University of California nor any of their employees, makes any warranty, express or implied, or assumes any legal liability or responsibility for the accu racy, completeness, or usefulness of any information, apparatus, product, or process disdosed, or represents that its use would not infringe privately owned rights. Reference herein to any specific commercia products, process, or service by trade name, trademank, manufacturer, or otherwise, does not necessarily constitute or imply its end or sement, recommendation, or favoring by the United States Government or the University of California. The views and opinjons of authors expressed herein do not necessarily state or reflect those of the United States Government or the Ciniversity of Califormia, and shall not be used for advertising or product endorsement purposes. 


\title{
PRECISION AND MANUFACTURING AT THE LAWRENCE LIVERMORE NATIONAL LABORATORY
}

\author{
Theodore T. Saito, Richard J. Wasley, Irving F. Stowers, \\ Robert R. Donaldson and Daniel C. Thompson \\ Energy, Manufacturing \& Transportation Technologies \\ Lawrence Livermore National Laboratory \\ P.O. Box 808, L-644 \\ Livermore, CA 94551 \\ Internet: SAITO1@LLNL.GOV
}

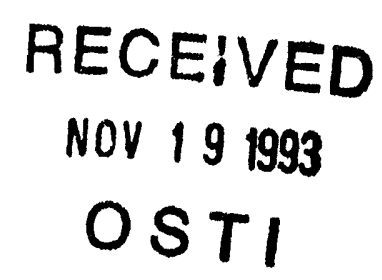

\begin{abstract}
Precision Engineering is one the Lawrence Livermore National Laboratory's core strengths. This paper discusses the past and present current technology transfer efforts of LLNL's Precision Engineering program and the Livermore Center for Advanced Manufacturing and Preductivity (LCAMP). More than a year ago the Precision Machining Commercialization project embodied several successful methods of transferring high technology from the National Laboratories to industry. Currently LCAMP has already demonstrated successful technology transfer and is involved in a broad spectrum of current programs. In addition this paper discusses other technologies ripe for future transition including the Large Optics Diamond Tuming Machine.
\end{abstract}

\section{INTRODUCTION}

The Lawrence Livermore National Laboratory (LLNL) is well known for the successful application of scientific principles to the solution of key technical problems and has addressed problems outside of the Department of Energy (DOE) for several decades. However, recint changes in legislation and national emphasis has opened up our doors to a broader spectrum of users.

LLNL's traditional mission of designing strategic weapons is changing, and economic competitiveness, particularly in advanced manufacturing, is becoming a new mission at Livermore. LLNL has unique capabilities in advanced manufacturing and supporting technologies that are strategically important to the competitiveness of key U.S. industries; e.g., automotive, machine tool, textile, consumer electronics, shipbuilding, computers, and aerospace. Expertise in technologies centrally important to advanced manufacturing include machine design, precision engineering, control systems, materials engineering, metrology, nondestructive cvaluation, process modeling, and structural modeling. Furthermore LLNL has worked with many large and small businesses in executing its major projects, such as the NOVA, terawatt laser. As LLNL adjusts to new roles and missions it will build on its solid relations with industry and transfer its technology to help American industry be more competitive. Just as Livermore played a key role in the cold war, it looks forward to playing a key role in the economic battle of today and tomorrow.

This paper will describe just a portion of LLNL's contributions to NASA and the commercial community. Activities from both the Precision Engineering Program (PEP) and the Livermore Center for Advanced Manufacturing and Productivity (LCAMP) will he described. First a perspective on LLNL's technology transfer success will be given by a past effort. Then a recent program will be described, and finally other technologies ready for transfer will be outlined.

\section{PAST TECHNOLOGY TRANSFER - PRECISION ENGINEERING PROGRAM}

The Precision Engineering Program (PEP) mission is to develop and utilize precision enginecring deterministic principles to solve problems of national interesL. Precision engineering is one of LLNL's core strengths with many successful applications to Department of Energy (DOE) and Department of Defense (DOD) programs. In addition, PEP has worked closely with NASA and private industry to successfully solve their problems. PEP has been active in precision machine tool design, metrology, optics (design, diamond turning, polishing and coating), precision process development and technology transfer.

* This work was performed under the auspices of the U.S. Department of Energy by Lawrence Livermore National Laboratory under contract No. \#W-7405--Eng-48. 


\section{Precision Machining Commercialization}

LLNL has a long background of technology transfer and cooperation with industry. One such initiative, under the Precision Engineering Program, was the Precision Machining Commercialization (PMC) project funded by the USAF Manufacturing Technology (ManTech). ${ }^{1}$ PMC successfully commercialized diamond turning technology developed within the Department of Energy, with an initial application to the Department of Defense.

Recognizing the order of magnitude cost savings as well as significant technical flexibility afforded by diamond turning, the USAF chartered LLNL in conjunction with DOE's Y-12 facility in Oak Ridge, Tennessee, to transfer the technology from the laboratory into commercial use. PMC had four major thrusts:

1. Documentation of the Diamond Turning Process

2. Seminars and Workshops Given to Private Industry

3. Technical Assistance to Private Industry

4. Hardware Demonstration

Documentation: Diamond turning is a highly technical but deterministic fabrication process. (A deterministic process is one in which much can be quantitatively defined through a cause-and-effect relationship.) Therefore, it was amenable to written scientific analysis. As is often the case with technologies and processes pushing the state-of-the-art, many of the lessons learned were not documented, but "understood" by the practitioners. PMC's goal was to describe in two volumes of documentation ${ }^{2}$ the key elements of the processes and associated technologies important to the successful understanding of diamond turning.

Seminars and Workshops: PMC served the role of technology advocate, both explaining the intricacies of the technology as well as its advantages. In addition to technical meetings with professional societies, such as SPIE, the International Optical Engineering Society and Society of Manufacturing Engineers, PMC hosted workshops across the country. These workshops were sometimes held in cooperation with machine tool companies who were prospective providers of turn-key diamond turning systems. One of the most effective stimuli was from direct visits to prospective technology users either at the seminars and workshops or their own plants. Furthermore, endorsement of the Department of Commerce and the National Tool, Die and Precision Machining Association (NTDPMA) facilitated the acceptance of PMC's efforts.

Technical Assistance: Technical assistance took several forms. One was consultation with both machine tool companies and users. Key questions regarding the applicability and capabilities of diamond turning for users helped identify the high pay-off areas. Technical "how-to" questions were also answered for machine tool companies. In addition, technical support was provided to Air Force and Army ManTech partners pursuing diamond turning. Honeywell and Kollmorgen both had significant success in achieving in-house diamond turning capability and providing optics for Air Force and Army programs.

Hardware Demenstration: During the technical assistance phase it was often found that a key question arose regarding the possibility of diamond turning being able to achieve the required specifications. Therefore, PMC provided a demonstration component fabricated within the DOE community. In additon to delivering a part which demonstrated the required performance, PMC also identified what steps would be necessary to improve existing or planned commercial capabilities to satisfy the advanced requirements.

PMC had impressive successes. Just one small production run of several hundred infrared scanner mirrors saved $\$ 500 \mathrm{~K}$. This savings was due to both reduced figuring and coating costs in the fabrication process. Infrared systems, such as those used in Desert Storm, have benefited from diamond turning. Furthermore applications have expanded to non-military uses such as hard disk drive platters, copier optics, contact lenses, and inter-ocular lenses.

During PMC's execution, it became apparent that diamond turning offered special fabrication capability which would enable a revolutionary resonator optic applicable to high power lasers. Shortly thereafter, the Precision Engineering Program was asked to build a special machine, the Large Optics Diamond Turning Machine (LODTM) (which will be described later), for this purpose. 


\section{RECENT TECHNOLOGY TRANSFER INITIATIVES: LIVERMORE CENTER FOR ADVANCED MANUFACTURING AND PRODUCTIVITY}

LLNL is well positioned to support U.S. manufacturing competitiveness and accordingly has established the Livermore Center for Advanced Manufacturing and Productivity (LCAMP). The mission of LCAMP is to focus and leverage the Laboratory's resources, activities, and expertise in manufacturing technologies critical to U.S. industrial competitiveness. LCAMP provides a conduit to industry, through which industry needs and LLNL resources and core competencies are identified, communicated, and matched. These efforts have resulted in collaborations with industry, universities, colleges, and DOE in a set of broadly based technology transfer projects, including education and training programs in advanced manufacturing.

LCAMP has initiated over 20 projects with industry, coupling the various companies with Livermore's technologies for mutual benefit. The technologies not only include precision engineering thrusts, but also advanced material development and application; computer modeling of manufacturing processes; and testing, inspection, and nondestructive evaluation.

One recently completed example of a partnership was with a small California industrial tool company in which a new precision machining system was developed that can cut hard-to-machine materials such as ceramics, carbides, glasses, and plastics with an accuracy of $1 \mu \mathrm{m}$. Applications include cutting computer disk-drive recording heads made of alumina-titanium carbide and slicing large silicon wafers into chips in the semiconductor industry. This new machine is twice as accurate as the company's previous machine, and now is one of the most precise production units of its kind in the world and will enable the tool company to compete successfully against (primarily) foreign competition.

LLNL's precision engineering expertise had strong influence to the machine layout and overall design. This can be seen with the use of a "bridge" design for the X-axis indexing slide and with the use of an air bearing slide system for the $\mathrm{Y}$-axis slide. The bridge design allow's for increased dynamic and thermal stability over the company's original cantilever arrangement. The air bearing slide system, designed by LLNL, is a low friction slide that provides precise movement of the work piece, essential to providing the accuracy requirements of the machine.

LLNL engineers advised the tool company on how to systematically reduce as many sources of potential error as possible and economically reasonable. This was demonstrated to the company by applying deterministic manufacturing and precision engineering techniques to calculate stresses in structures, predict machine performance and thermal and vibration characteristics, and apply error-compensation methods to maximize system accuracy despite vibration and temperature fluctuations.

Along with the engineering design assistance, LLNL personnel provided hands-on assistance which included training and assembly of the $\mathrm{Y}$-axis air bearing slide system, instruction of precision alignment techniques and procedures, and the application of proper precision metrology. The partnership between LLNL and the company produced the successful fabrication and testing of a prototype machine leading to sales of production units.

In addition to generating joint projects with industry, LCAMP is developing other support mechanisms to enhance L.S. manufacturing competitiveness. For example, LLNL is creating user facilities that will be formally recognized by DOE for industry and university interactions. These facilities are underutilized, unclassified, have state-of-the-art manufacturing equipment, and are accessible by industrial personnel, students, and faculty for project work, research, education and training classes, demonstration efforts, and outreach activities.

L-CAMP has also been centrally involved in establishing Regional Technical Assistance Programs, e.g., the National Machine Tool Partnership (NMTP) and the Small Business Technology Transfer Program (SBTTP). The NMTP is a partnership among the four Defense Program National Laboratories (LLNL, Los Alamos National Laboratory, Sandia National Laboratory, and the Oak Ridge National Laboratory) together with DOE, DOC (NIST) and DOD. Its purpose is to strengthen the U.S. machine tool industry to help the U.S. regain its worldwide lead by providing free quick turnaround solutions to real world problems being experienced by builders and users. The SBTTP suppors smaller regional businesses (<500 employees) by providing free technical assistance (up to \$5K) and partnership agreements (up to $\$ 50 \mathrm{~K}$ ) to gain access to DOE facilities and equipment. 


\section{FUTURE TECHNOLOGY TRANSFER POSSIBILITIES}

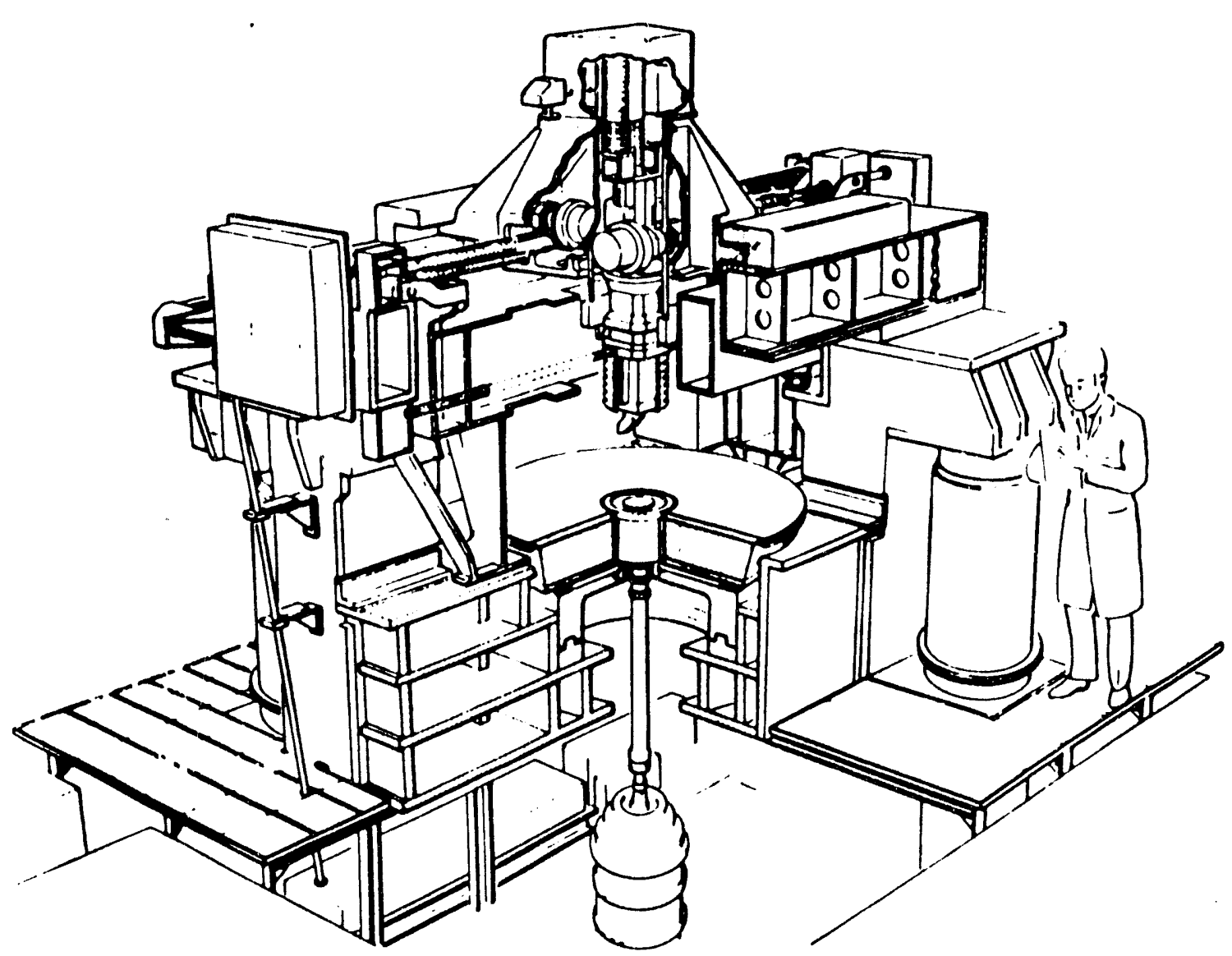

Figure 1.

The Large Optics Diamond Turning Machine

\section{LODTM}

As mentioned earlier, LLNL was asked in the late 1970's to design a state-of-the-art diamond turning machine for special DOD resonator optics for a space bome laser. This resulted in the Large Optics Diamond Turning Machine (LODTM) which is a precision vertical-axis lathe, stion $n$ in Fiz. 1. The workpice size limits are $162 \mathrm{~cm}$ in diameter, $50 \mathrm{~cm}$ in height, with a maximum weight of $1400 \mathrm{~kg}$. Tool positioning on the LODTM is accomplished by a vertical tool bar (Z-axis) motion and a carriage which provides radial ( $\mathrm{X}$-axis) motion. LODTM's development included many technologies which have been or are ripe for technology transfer.

A fundamental problem in the design of a high accuracy feedback-controlled machine tool is measuring the relative position between the tool and the workpiece without intruding into the work volume, which is occupied by the workpiece. The measurement scheme that connects the tool tip to the workpiece is referred to as the 'metrology loop.' For the LODTM the active measurements are made by laser interferometers and capacitance gages, which are referenced to a passive metrology frame.

The metrology frame interconnects the interferometers and capacitance gages and surrounds the machine work zone, as shown in Fig. 1. To perform its intended function, the metrology frame must remain exactly constant in size and shape even though the mainframe may deform by up to $6 \mu \mathrm{m}$. Super Invar is used to provide a dimensionally stable structure with a low coefficient of thermal expansion. 
All large-travel measurements are made by means of seven laser interferometers, each with a resolution of $1.2 \mathrm{~nm}$ and overall accuracy of $2.5 \mathrm{~nm}$. Great care has been taken in developing a single frequency-stabilized laser and to minimize interferometer errors due to uncertainties in the index of refraction in the interferometer leg. The interferometric measurements are isolated from atmospheric effects by enclosing all but a tiny gap of the interferometer measurement pathway in vacuum.

Workpiece position, relative to the metrology frame, is determined by capacitance sensors mounted on metrology frame extensions, which measure drift of the outer edge of the spindle face plate. Two orthogonal capacitance gages at each edge of the face plate provide axial, radial, and tilt motion data with a resolution of $0.6 \mathrm{~nm}$ and a $0.1 \%$ linearity.

The design of moving parts for the LODTM relies heavily on the use of fluid film bearings for smooth, friction-free motion. To avoid pump vibrations, the oil systems are fed by pairs of blow-down tanks that are alternately pressurized by compressed air.

The primary actuators for both $\mathrm{X}$ and $\mathrm{Z}$ axis motion are capstan drives, each consisting of a $5 \mathrm{~cm}$ diameter smooth steel rollers driving against a flat steel bar approximately $2.5 \mathrm{~cm}$ wide. The roller is supported by externally pressurized oil bearings, and is driven directly by a DC motor, with a large DC tachometer for velocity feedback and a servo control system. The least increment for the computer control system driving the two axes is $2.5 \mathrm{~nm}$.

Vibration and temperature are also carefully controlled. For vibration isolation, the LODTM mainframe rests on four air isolators, two of which have been connected together to provide a three-point kinematic support. The selfleveling pneumatic isolators have very low natural frequencies, well below LODTM's structural vibration modes. Since temperature control is crucial for achieving the required accuracy, the ambient temperature is maintained constant within $0.005^{\circ} \mathrm{C} \mathrm{p-v}$ and an air flow rate of $6 \mathrm{~m}^{3} / \mathrm{s}$. Critical LODTM components are also temperature controlled directly by water flow whose temperature is held constant to $0.0005^{\circ} \mathrm{C} \mathrm{p}-\mathrm{v}$. The temperature stabilized water is gravity fed to avoid pump vibrations and temperature stabilizes the spindle thrust bearing stator, journal bearing stator and the metrology frame.

With the aid of the above (and other) technical features, the LODTM is capable of machining reflective metal optical surfaces to an rms figure accuracy of better than 1/25th of the wavelength of visible light (about $25 \mathrm{~nm} \mathrm{rms}$ ) with a surface roughness of about $5.0 \mathrm{~nm}$ rms. An interesting example of work done on the LODTM is a secondary mirror for the Keck Telescope, a major ground-based astronomical observatory located atop Mauna Kea in Hawaii. The secondary mirror is $50 \mathrm{~cm}$ in diameter, and collects light reflected from the $10 \mathrm{~m}$ Keck primary mirror. The mirror is a convex hyperboloid with a scalloped oulline which follows the irregularities resulting from the primary mirror being made up of 36 hexagonal segments. Figure 2 shows the mirror being measured by the LODTM after diamond turning. The figure accuracy was found to be about $\lambda / 40 \mathrm{rms}$ (He-Ne wavelength), and the mirror finish (evident by reflections in the surface) was adequate for the intended use in the near-infrared regime without any subsequent optical polishing. The figure accuracy extends clear to the mirror edge; it is an attractive feature of diamond turning that accuracy can be maintained in the presence of the interrupted cut caused by the scalloped edge.

In addition to the infrared secondary for the Keck telescope, LODT.M has successfully diamond turned a wave front corrector, a non-rotationally symmetric optic ${ }^{3}$. A wave front corrector is a component of a telescope on which the primary can be imaged. Compensation of the errors in the primary can be achieved by fabricating the appropriate "anti-errors" into the wave front corrector, thus achieving correction over a modest ficld of view. This concept was demonstrated using the designs of Stacey, Meinel, and Meinel of NASA's Jet Propulsion Laboratory, and LODTM. The surface $\mathrm{z}$ of the optic can be described using Zernike polynomials:

(1) $z=1.73 \lambda r^{2} \cos 2 \theta+\lambda r^{2} \sin 2 \theta+2 \lambda\left(3 r^{2}-2\right) r \cos \theta$

where $\mathrm{z}, \mathrm{r}$, and $\theta$ are cylindrical coordinates and $\lambda=0.63 \mu \mathrm{m}$. LODTM diamond turned this unusual figure to $\lambda / 10 \mathrm{rms}$. 


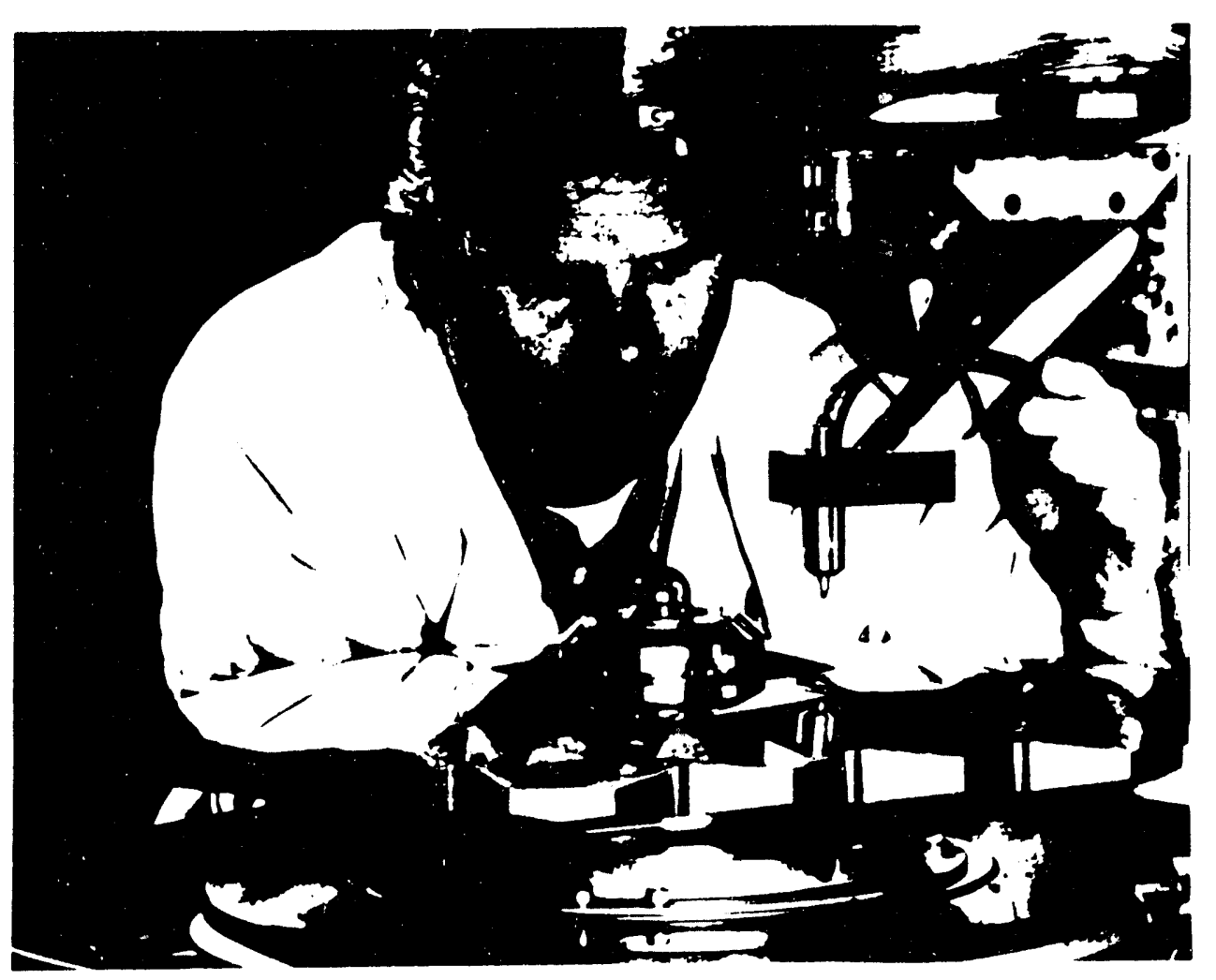

Figure 2.

The infrared Keck secondary being measured on LODTM.

\section{Ducule Grinding Research}

Single-point diamond turning (SPD'T) is now a mature technology capable of producing components with a contour accuracy approaching $20 \mathrm{~nm}$ rms and a surface finish approaching $5 \mathrm{~nm}$. However, due to the fragile nature of the single-point diamond cutting tool and its chemical affinity with ferrous materials and glass the process has been striculy limited to non-ferrous soft metals such as copper, electroless nickel, aluminum, gold, silver and a handful of soft crystalline materials such as KDP4,5. It is unfortunate that a similar process for economically and rapidly contouring ceramic materials such as silicon carbide, fused silica, LLE, Zerodur and ferrites 6,7 does not exist. The soft non-ferrous melals are appropriate for the cunstructwon of near infrared high fluence cooled optics for imaging and laser resonator cavities, whereas the ceramic materials are highly desirable where low expansion and high precision components, such as Wolter grazing incidence telescopes, high temperature roller bearings, surveillance optics, and magnetic recording heads are needed.

The SPDT process can be highly cost effective for the fabrication of precision components of unusual shape compared with conventional grinding and polishing processes because it is a deterministic process. Determinism results in the ability to prescribe a contour in space with a single-point diamond tool (mounted to a computer controlled machine tool) and to have the resultant workpiece achieve this contour within the desired specification. Non-determinism as in conventional grinding results from the grinding process actually removing more than the depth of cut as a result of surface fracturing and spallation. Polishing is also a non-deterministic process that relies on the conformance of a lap, embedded with abrasive, to match the contour of the workpiece and to more rapidly remove those areas where the workpiece contour deviates from the lap contour. In addition, conventional grinding and polishing are less productive than SPDT because in-situ metrology has been difficult to integrate into the polishing process and must occur or f-line. 
During the past five years it has become more obvious that ultra-precision grinding (a.k.a. ductile grinding, shear mode grinding, or nanogrinding) could revolutionize the precision machining industry by allowing the rapid deterministic contouring of metals, britule ceramic and glass materials. The often reported observation is that when very fine abrasives $(1-2 \mu \mathrm{m})$ are employed in conjunction with precise control of the depth-of-cut a non-brittle material removal process (thus the name ductile grinding) ensues with low surface roughness and low subsurface damage. The observation of a brittle-to-ductile transition with a single-point indentor has been known for over 30 years; however, only recently has this knowledge been applied to the continuous grinding process $8,9,10$. A complete understanding of how and under what circumstances this transition occurs will lead to a manufacturing process able to economically fabricate ceramic materials to nanometer contour accuracy 11,12 .

LLNL has demonstrated a ground surface roughness on BK-7 and LG-750 of $0.4 \mathrm{~nm} \mathrm{rms} 13,14,15$. This process combines precision contour grinding and final polishing on a single grinding machine. As part of this same work these ultrasmooth surfaces have demonstrated a laser damage threshold at least as high as the best conventionally polished optics (17 J/ $\left.\mathrm{cm}^{2} @ 1 \mathrm{~ns}\right)^{16}$.

The deterministic nature of the ductile grinding process (that it can be done with a precision contoured grinding wheel with high peripheral speed on a very rigid machine) coupled with the in-situ laser displacement metrology that is now common to all precision machine tools, Icads to at least an order of magnitude higher overall productivity compared with conventional grinding and polishing and places it on a par with the productivity of diamond turning.

Potential commercial markets for ductile grinding are the economic fabrication of precision ceramic roller bearings, optical components for night-vision optics, and any optical component that would benefit from the replacement of up to four spherical optics with a single aspheric optic such as lightweight optics for spacecraft instrumentation or for portable optics for military troops.

\section{Molecular Dynamics Modeling}

Although single-point diamond turning is now becoming widely used in industry, little is understood of the tool-to-workpiece interaction, workpiece deformation, magnitude of residual stresses, and the nature of tool wear. Understanding tool wear and how to prevent or control it would substantially expand the variety of materials that could be successfully diamond turned. A detailed understanding of wear, however, would profit from the development of an atomistic description of material deformation and chemical interactions.

LLNL has applied the molecular dynamics (MD) modeling technique to understand the deformation of metals and ceramics subjected to sharp cutting tools as in high-speed single-point diamond turning. LLNL has developed several sophisticated molecular dynamics computer simulation codes and have begun to investigate the cutting of copper, silicon, and silica with diamond tools.

The precision machining of metal surfaces and the precision grinding of glass and ceramics are similar in that both can be viewed as being an orthogonal cutting process. For this reason and because fracture and plastic flow are inherendy atomistic in nature rather than continuous as assumed by continuum mechanis, deformation is being modeled using realistic many-body atomistic interaction potentials and state-of-the-art computational techniques.

Recently, it has become possible to construct large-scale MD computer simulations of the orthogonal cutting of simple metals $17,18,19,20,21,22$. LLNL has constructed such a simulation of the steady-state orthogonal cutting of single crystal copper. The model reveals considerable information on the evolution of chip morphology, chip stress, temperature distribution, and the effect of tool sharpness (edge radius) on cutting force and specific energy. The ability to model the cutting process with a depth of cut of $20 \mathrm{~nm}$ has allowed our cutting force and specific energy predictions to be directly compared with recently reported ultra-precision machining experiments utilizing singlepoint diamond tools.

Utilizing these computer models LLNL has found, for example, that the specific energy necessary to cut a surface increases exponentially with a decrease in the depth of cut. At very shallow depth of cut the energy input is equal to the energy necessary to evaporate the material off of the surface. LLNL has also found that during the machining of single crystal silicon the diamond cutting tool chemically reacted with the silicon to form a silicon 
14 K. L. Blaedel, R. W. Clouser, P. J. Davis, "Ductile Grinding of Glass," Thrust Area Report FY87 - Engineering Research and Development, (Apr. 1988). pp. 6-1-6-5. (UCRL-53868-87).

15 K. L. Blaedel, P. J. Davis, J. Franse, "Ductile Grinding of Brittle Matcrials," Thrust Area Report FY88 - Engineering Research and Development, (Jun. 1988). pp. 4-26-4-28. (UCRL-53868-88).

16 K. L. Blaedel, P. J. Davis, D. J. Nikkel, "Ductile Grinding of Brittle Materials," Thrust Area Report FY89 Engineering Research and Development, in publication. (UCRL-53868-89).

17 W.G. Hoover, C.G. Hoover, I.F. Stowers, W.J. Siekhaus, "Interface Tribology by Nonequilibrium Molecular Dynamics", Mat. Res. Soc. Symp., Vol 140, Boston, MS, 1989. pp. 119-124.

18 W.G. Hoover, C.G. Hoover, I.F. Stowers, A.J. De Groot, B. Moran, "Simulation of Mechanical Deformation via Nonequilibrium Molecular Dynamics", CECAM Workshop on Microscopic Simulation of Macroscopic Flows, Brussels, Belgium, Aug. 1989.

19 W.G. Hoover, C.G. Hoover, A.J. De Groot, B.L. Holian, I.F. Stowers, T. Kawai, "Million-Atom Plain Strain Indentation Studies via Nonequilibrium Molecular Dynamics", Third Workshop on Molecular Simulations, Kyoto University, Japan, 1990. pp. 55-56.

20 W.G. Hoover, A.J. De Groot, C.G. Hoover, I.F. Stowers, T. Kawai, B.L. Holian, T. Boku, S. Ihara, J. Belak, "LargeScale Elastic-Plastic Indentation Simulations via Nonequilibrium Molecular Dynamics", Physical Review A, 10 (42), 1990, pp. 5844-5853.

21 J.F. Belak, I.F. Stowers, "Molecular Dynamics Studies of Surface Indentation in Two Dimensions", Atomic Scale Calculations of Structure in Materials, Vol 193, San Francisco, CA, Apr. 16-21, 1990. pp. 259-264. Materials Research Society.

22 J.F. Belak, I.F. Stowers, "A Molecular Dynamics Model of the Orthogonal Cutting Process", ASPE Annual Conference, Rochester, NY, Sept. 23-28, 1990. pp. 76-79. ASPE, PO Box 7918, Raleigh, NC 27695. 

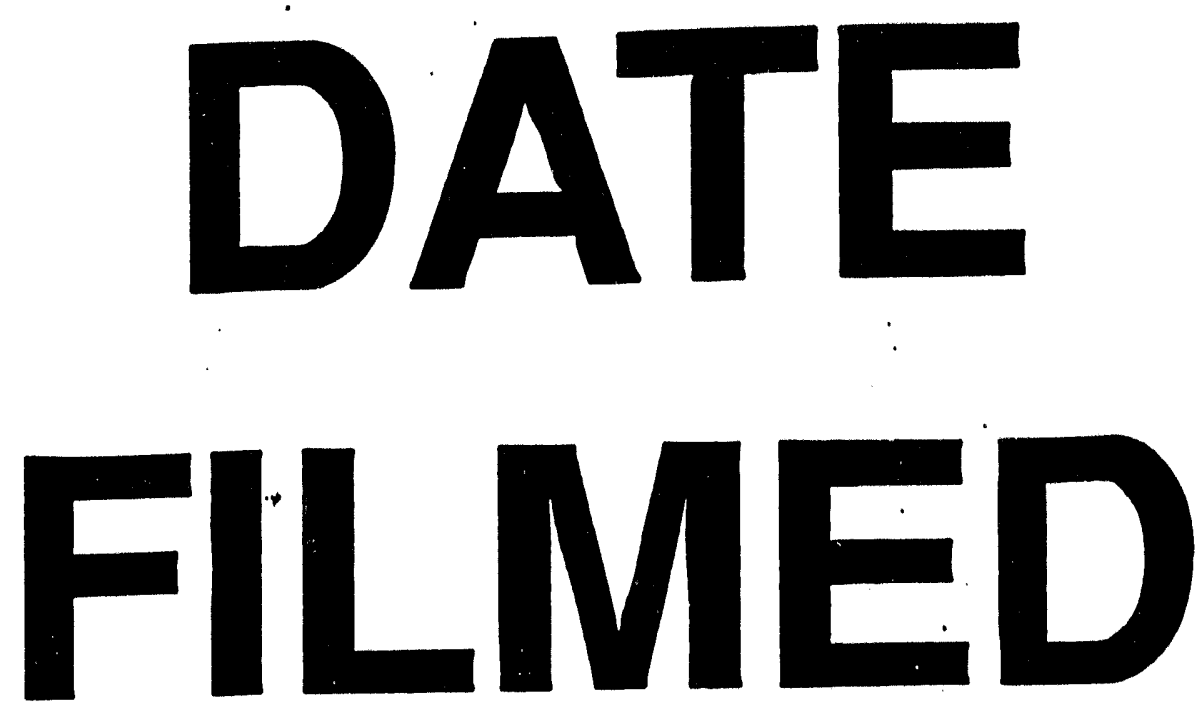

I

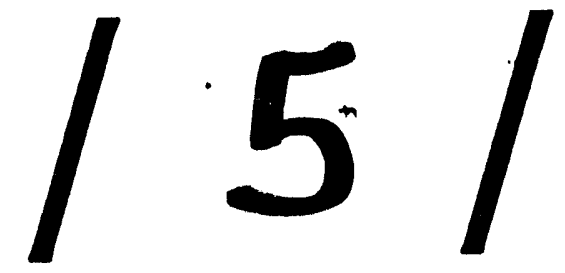

94
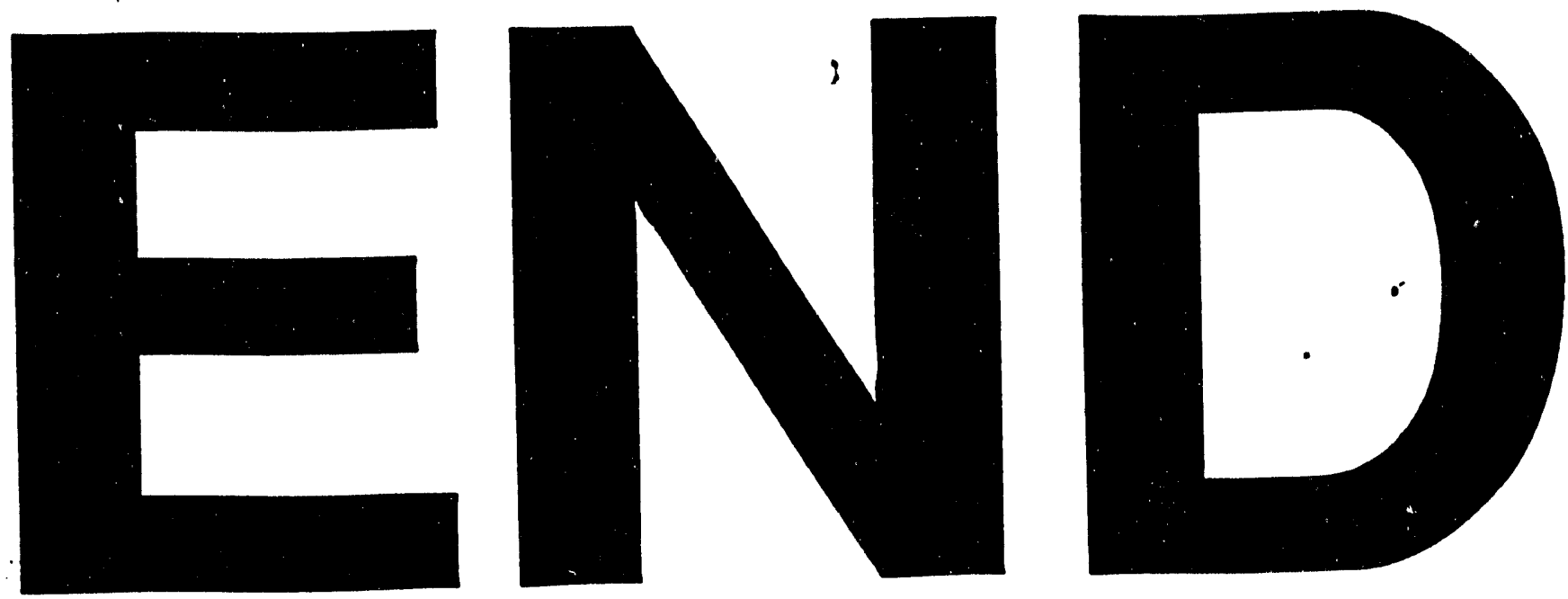
